\title{
HET UNIVERSALISME VAN DE BERGREDE IN HET VERHAAL VAN MATTHEÜS ${ }^{1}$
}

\author{
Boris Paschke \\ Evangelische Theologische Faculteit \\ Leuven
}

\begin{abstract}
Mt 5:13-16 is studied with regard to universalism and interpreted in the context of the Matthean narrative. In this passage, Jesus entrusts his disciples with a centrifugal ministry that addresses Jews and Gentiles alike and that is to be carried out immediately after the Sermon on the Mount (Mt 5-7). Mt 5:13-16 thus stands in tension to the established scholarly view that the disciples carry out a universal mission only after Jesus's resurrection (cf. Mt 28:19). The universalism of Mt 5:1316 rather suggests to divide the Matthean narrative into a universalistic beginning, a particularistic interim time (cf. Mt 10:5-6), and a universalistic open end.
\end{abstract}

Key Words (English): Matthean story; mission; Sermon on the Mount; universalism

Sleutelwoorden (Afrikaans): berg preek; besending; storie van Matteus; universalisme

Op basis van de uitspraken van de Mattheaanse Jezus over zijn eigen zending en die van zijn discipelen deelt de meerderheid van exegeten het verhaal van Mattheüs in twee fasen in: ${ }^{2}$ Een fase voor en een fase na de kruisiging/opstanding van de Mattheaanse Jezus. Volgens de meeste uitleggers is de eerste fase particularistisch: De bediening van Jezus en zijn discipelen is alleen maar voor het volk Israël bedoeld (Mat. 10:5-6; 15:24). De tweede fase wordt als universalistisch beschouwd: Alle volken zijn de geadresseerden van de bediening van Jezus' discipelen (Mat. 28:19). Wim Weren vat deze tweedeling als volgt samen:

Op het einde van het boek worden de elf uitgestuurd naar alle volkeren, terwijl de zendingsrede hun missie beperkt tot de verloren schapen van het huis van Israël $(10,6)$.

Deze gegevens met elkaar combinerend zou men kunnen denken dat er sprake is van twee op elkaar volgende stadia. De zendingsrede zou betrekking hebben op een eerste fase, waarin de leerlingen nog alleen in Israël actief zijn, terwijl 28,16-20 een nieuwe fase inluidt, waarin ze hun werkterrein verbreden tot alle volkeren (Weren 1994:99).

In plaats van particularisme en universalisme zien enkele uitlegers in de eerste en tweede fase van het verhaal van Mattheüs respectievelijk een centripetaal en centrifugaal universalisme (vgl. Paschke 2011). Centrifugaal universalisme betekent dat de Mattheaanse

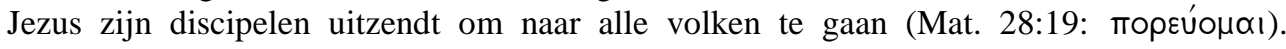
Centripetaal universalisme wil zeggen dat Jezus en zijn discipelen wel gezonden zijn om -

Ik dank mijn collega drs. Jermo van Nes dat hij het Nederlands van dit artikel verbeterd heeft.

Zoals het woord 'verhaal' impliceert wordt het evangelie van Mattheüs in dit artikel narratief-kritisch benaderd (vgl. Kingsbury 1988; Luz 2008; Smit 2007). Als gevolg doelen verwijzingen naar 'fasen' altijd op fasen van het Mattheaanse verhaal. De vraag in hoeverre deze verhaalfasen met historische fasen van het leven van Jezus en zijn discipelen overeenstemmen komt in dit artikel niet aan bod. 


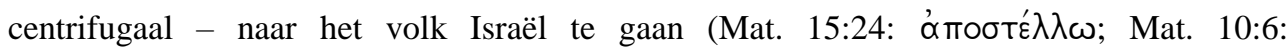
порєúo $\alpha_{1}$ ), maar dat van heidenen verwacht wordt dat zij - centripetaal - naar Jezus en zijn discipelen komen (vgl. bijv. Mat. 2:1-12; Mat. 8:5-13; Mat. 15:21-28). In zijn commentaar op Mat. 28:19 vat Guido Tisera deze tweedeling als volgt samen: 'The charge "go" constitutes a distinctive pattern if compared to the universalism prior to this. Before this, the pattern is centripetal, but now centrifugal' (Tisera 1993:314).

Helaas moet men constateren dat in het onderzoek naar het evangelie van Mattheüs de tweedeling van het Mattheaanse verhaal in of (1) particularisme en universalisme of (2) centripetaal universalisme en centrifugaal universalisme slechts gebaseerd is op een beperkt aantal Mattheaanse teksten. Tisera merkt op: 'The dominant concern is still with certain passages that show an apparent tension between particularism (Matt 10,5b-6; 15,24) and universalism (Matt 28,16-20) while other passages are not given a proper examination' (Tisera 1993:11-12).

Zo maakt de Bergrede (Mat. 5-7) onderdeel uit van de passages die tot voor kort nauwelijks onderzocht zijn wat betreft de Mattheaanse spanning tussen particularisme en universalisme enerzijds en centripetaal en centrifugaal universalisme anderzijds. Ondanks zijn belofte alle relevante passages te bestuderen (Tisera 1993:1) ziet Tisera de Bergrede zelf over het hoofd. Ook andere monografieën over Mattheaans particularisme en universalisme (bijv. Levine 1988; Konradt 2007) geven onvoldoende aandacht aan de Bergrede, terwijl deze toespraak diverse passages bevat die relevant zijn voor deze thematiek. Te denken valt bijvoorbeeld aan: (1) Mat. 5:13-16; (2) de geringschattende uitspraken van Jezus over de heidenen (Mat. 5:47; 6:7-8, 31-32); (3) Mat. 7:6 en (4) Mat. 7:24-27. Terecht zegt Johannes Nissen over de eerst genoemde passage: 'The mission discourse in ch. 10 and the final commission in ch. 28 are usually considered to be the two most important mission texts in the first Gospel. Matt 5:13-16 is a third text the significance of which for Matthew's theology of mission has largely been overlooked' (Nissen 1999:27).

Alle boven genoemde teksten werden in mijn recente monografie Particularism and Universalism in the Sermon on the Mount (Paschke 2012) in detail onderzocht, met als resultaat de vaststelling dat in de Bergrede een centrifugaal universalisme tot uitdrukking wordt gebracht en dat Jezus zijn discipelen opdraagt zich in hun bediending tot zowel joden als heidenen te richten. Daarmee staat de Bergrede op gespannen voet met een tweedeling van het verhaal van Mattheüs in een fase voor en een fase $n a$ de kruisiging/opstanding van Jezus. Naar mijn idee zou men op basis van de Bergrede het verhaal van Mattheüs beter in de volgende drie fasen kunnen indelen: Een universalistisch begin (Mat. 4:18-10:4), een particularistische tussentijd (Mat. 10:5-28:17) en een universalistisch open eind (Mat. 28:18-20).

In dit artikel zal de inhoud van mijn monografie aan de hand van Mat. 5:13-16 worden voorgesteld, aangevuld en voor een Nederlands-/Afrikaanstalig publiek toegankelijk gemaakt. De opbouw van het artikel is als volgt: ten eerste zal worden aangetoond dat de Mattheaanse Jezus zijn discipelen in Mat. 5:13-16 een universalistische bediening opdraagt. Ten tweede zal worden beargumenteerd dat deze universalistische bediening centrifugaal is. Tot slot zal worden aangetoond dat de discipelen met hun universalistische en centripetale bediening meteen na afloop van de Bergrede, d.w.z. al heel vroeg in het Mattheaanse verhaal, moeten beginnen en dat Jezus hun universele zending pas in Mat. 10:5-6 tot een particularistische zending beperkt. Teksten uit het Griekse Nieuwe Testament zijn afkomstig uit de $28 \mathrm{e}$ editie van de Novum Testamentum Graece. Indien niet anders vermeldt zijn Nederlandse Bijbelteksten afkomstig uit de Nieuwe Bijbelvertaling. 


\section{De reikwijdte van de apostolische bediening}

In Mat. 5:13-16 geeft Jezus zijn discipelen aanwijzingen wat betreft hun bediening. Volgens Mat. 5:16 bestaat deze in de eerste instantie uit 'goede daden' ( $\kappa \alpha \lambda \alpha$ verband zijn er vier aanwijzingen die de reikwijdte van de apostolische bediening aangeven. Bij alle vier is er sprake van universalisme.

$\gamma \hat{\eta}$

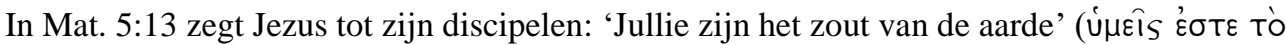
$\left.\alpha^{\prime \prime} \lambda \alpha_{S} T \hat{\eta} S \gamma \hat{\eta} s\right)$. De belangrijkste exegetische vraag voor het onderwerp van dit artikel is of $\gamma \hat{\eta}$ 'land' of 'aarde' betekend. Sommige exegeten gaan ervan uit dat Jezus in Mat. 5:13 met $\gamma \eta \hat{\eta}$ het land Israël bedoelt (vgl. Dumbrell 1981:13; Beutler 1994; S̆oltés 2004:111) en zijn discipelen daarmee dus een particularistische zendingsopdracht geeft (Šoltés 2004:109). Het gebruik van $\gamma \hat{\eta}$ in de rest van het evangelie van Mattheüs spreekt deze interpretatie echter tegen: Het woord is een uitdrukking voor (1) de aarde (Mat. 17:25; 24:30), vaak in tegenstelling tot de hemel (Mat. 5:18, 35; 6:10, 19; 11:25; 16:19; 18:18; 23:9; 24:35; 28:18); (2) land, in contrast met de zee (Mat. 14:24, 34); (3) een akker/stuk land (Mat. 13:5, $8,23)$; (4) de grond (Mat. 10:29; 15:35; 25:18, 25); en (5) een specifieke regio of land. In het laatste geval wordt de bedoelde regio altijd expliciet aangegeven, zoals dit bijvoorbeeld in Mat. 2:20-21 gebeurt waar twee keer het 'land Israël' ( $\gamma \hat{\eta}$ ' lopaŕ $\lambda$ ) genoemd wordt (vgl. verder Mat. 2:6; 4:15; 10:15; 11:24). Donald A. Carson schrijft: 'In Matthew ... gē is used to refer to a specific region or nation (Israel, Judah, Zebulon, Naphtali et al.) only if that region's name is given' (Carson 1984:136). Op basis van het onderzoek naar het woord $\gamma \hat{\eta}$ in het evangelie van Mattheüs is het dus niet aannemelijk dat $\gamma \eta$ in Mat. 5:13 naar het land Israël verwijst. Veeleer bedoelt Jezus hiermee de aarde, iets wat trouwens ook het geval is in Mat. 5:5 waar de landbelofte uit Ps 36:11 (Septuagint) in overeenstemming met joodse (Jub 32:18-19) en andere vroegchristelijke (Rom. 4:13) teksten universalistisch bedoeld is (vgl. Luz 2007:194-195). Het is dus waarschijnlijk dat Jezus in Mat. 5:13 met $\gamma \hat{\eta}$ de aarde ${ }^{3}$ bedoelt en over de universalistische bediening van zijn discipelen spreekt (vgl. Luz


een betrekking tussen leerlingenkring en mensenwereld tot uitdrukking gebracht' (Henau 1985:47; vgl. Grosheide 1954:72).

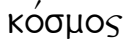

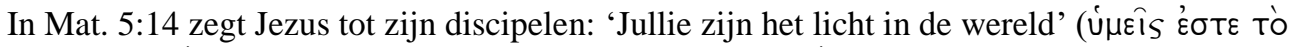

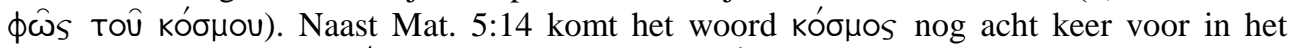

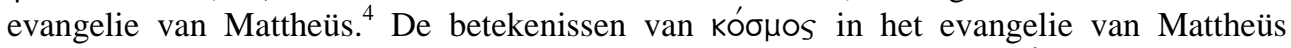

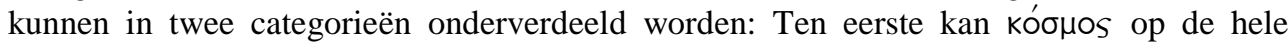
schepping/het heelal duiden (Mat. 24:21; 25:34; vgl. ook Mat. 13:35). In de tweede plaats

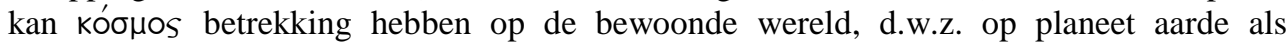
woonplaats van mensen (Mat. 4:8; 13:38; 26:13), op aardse vreugden (Mat. 16:26) of op de mensheid op zich (Mat. 18:7). In Mat. 5:13 valt de betekenis van kóouos in de tweede categorie. In de onmiddellijke context worden zowel 'mensen' (Mat. 5:16) als bepaalde

De gangbare Nederlandse Bijbelvertalingen (zoals NBG; NBV; Statenvertaling; Herziene Statenvertaling; Willibrord-vertaling) vertalen $\gamma \hat{\eta}$ met 'aarde'; te ver gaan de Groot Nieuwsbijbel en Het boek wanneer zij $\gamma \hat{\eta}$ in Mat. 5:13 met 'wereld' vertalen.

4 Waarbij het gebruik in Mat. 13:35 tekstkritisch gezien twijfelachtig is. 
dingen/voorwerpen van de menselijke civilisatie genoemd (Mat. 5:14: 'stad'; Mat. 5:15:

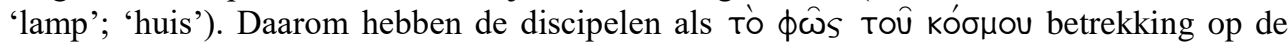
'mensenwereld' (Grosheide 1954:73; vgl. Keulers 1950:70) en hun bediening is dus universalistisch (Gnilka 1993:135). In zijn commentaar op Mat. 5:14 spreekt Herman Ridderbos van 'de betekenis en ... taak der discipelen in de wereld' (Ridderbos 1952:99).



In Mat. 5:15 illustreert Jezus de rol van zijn discipelen aan de hand van het beeld van een

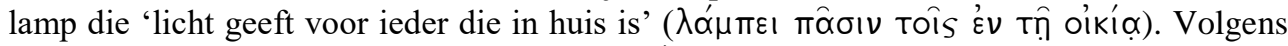

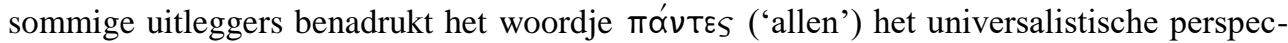
tief van het beeld van de lamp (bijv. Luz 2007:207). Anderen komen ondanks пর́ $\nu T \varepsilon s$ tot de conclusie dat de frase Tá 'huis' (o’kí) als een referentie naar het 'huis Israël' opvatten (Šoltés 2004:206-207; Manson 1979:93). Het Griekse woord oíkos kan zowel in de Septuagint als in het evangelie van Mattheüs naar het 'huis Israëls' verwijzen. Het is echter belangrijk om te benadrukken dat in al deze gevallen sprake is van oîkos' lopań (vgl. Lev 10:6; Num 20:29; Ruth 4:11, Amos 5:25; Mat. 10:6; 15:24). Dus enkel het woord oikí in Mat. 5:15 kan niet zo maar in de zin van 'huis Israëls' worden geïnterpreteerd. Bovendien wordt in Mat. 5:15 niet oîkos maar oikía gebruikt. De mogelijke betekenis 'huis Israëls' van de eerste term mag niet zo maar naar de tweede getransfereerd worden. Dit wordt door zowel de Septuagint als het evangelie van Mattheüs bevestigd. In de Septuagint wordt het woord oikí nergens als referentie naar het 'huis Israëls' gebruikt. De term oikía' lopań $\lambda$ is in de Septuagint niet te vinden. In het evangelie van Mattheüs komt oikía naast Mat. 5:15 vijfentwintig keer voor. ${ }^{5}$ In negentien gevallen verwijst oikía letterlijk naar een 'huis', d.w.z. naar een gebouw. ${ }^{6}$ In de resterende vijf gevallen doelt oikía op een gezin/familie. ${ }^{7}$ Nergens in het evangelie van Mattheüs heeft o'kía de betekenis 'huis Israëls'. Op basis van dit onderzoek naar het woord oíía in de Septuagint en het evangelie van Mattheüs ligt het minder voor de hand oikía in Mat. 5:15 als referentie naar het 'huis Israëls' op te vatten. Donald A. Hagner zegt dat de frase тóv restrictive sense' (Hagner 1993:100). Veeleer is het met het oog op het door $\gamma \hat{\eta}$ (Mat. 5:13)

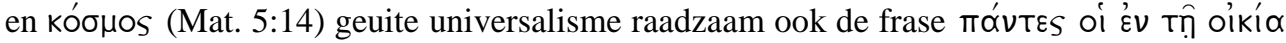
(Mat. 5:15) universalistisch te interpreteren. Alexander Sand schrijft: 'Allen im Hause, und dies sind nach Mt die Bewohner des (ganzen) Kosmos, muß das Licht leuchten (Sand 1986:105).'

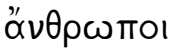

In Mat. 5:16 zegt Jezus tot zijn discipelen: 'Zo moet jullie licht schijnen voor de mensen

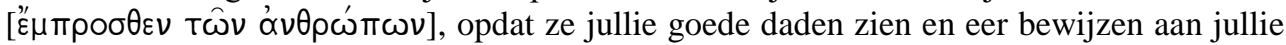
Vader in de hemel.' In de grote meerderheid van het Mattheaanse gebruik van $\alpha \nu \theta \rho \omega \pi$ ' betekent dit woord over het algemeen 'mens'. In sommige gevallen staat er bij 'o een lidwoord, d.w.z. ó ơ $v \theta$ pw

\footnotetext{
Waarbij het voorkomen in Mat. 23:14 waarschijnlijk geen deel van de oorspronkelijke tekst uitmaakt (vgl. Metzger 1994:50).

$6 \quad$ Mat. 2:11; 7:24-27 (vier voorkomen); 8:6, 14; 9:10, 23, 28; 12:29 (twee voorkomen); 13:1, 36; 17:25; 19:29; 24:17, 43; 26:6; vgl. Mat. 23:14.

7 Mat. 10:12-14 (drie voorkomen); 12:25; 13:57.
} 
zichzelf of de mens collectief. In andere gevallen staat ${ }^{\prime \prime} \nu \theta \rho \omega \pi$ \% in contrast met dieren (Mat. 4:19: vis; Mat. 12:12: schaap) of God, d.w.z. een goddelijke wezen (Mat. 16:23; 19:6, 26; 22:16; cf. 21:25). Ook in deze gevallen doelt $\alpha$ gevallen waar $\alpha$ $\nu \theta \rho \omega \pi$ ToS in enge zin gebruikt wordt, blijkt dit uit de context: in Mat. 19 betekent ' $\alpha \theta \rho \omega \pi$ os enkele keren 'echtgenoot/man' (Mat. 19:3, 5, 10). In andere gevallen verwijst "̊ $v \theta \rho \omega \pi$ Tos specifiek naar joodse personages van het Mattheaanse verhaal

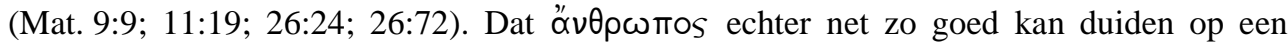
heidens personage blijkt uit de uitspraak van de hoofdman te Kafarnaüm: 'Want ook ik ben

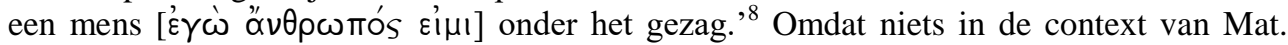
5:15 op een enge betekenis van $\alpha 2 \theta \rho \omega \pi$ Tos wijst is het voor de hand liggend dit woord hier als een term voor mensen in het algemeen op te vatten. Henry Pattarumadathil schrijft in zijn commentaar op Mt 5:16: 'Jesus does not identify any special group of people whom the disciples should inspire and influence to glorify the Father; rather he uses a generic term "men" (" $\nu \theta \rho \omega \pi$ I) to refer to them' (Pattarumadathil 2008:96). De woorden of " $\alpha \theta \rho \omega \pi$ । in Mat. 5:16 benadrukken dus - in overeenstemming met $\gamma \hat{\eta}$ (Mat. 5:13), kóouos (Mat.

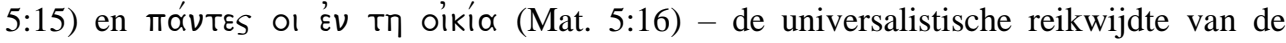
bediening van Jezus' discipelen. Henau schrijft met betrekking tot Mat. 5:16: “'Voor de ogen van de mensen' betekent: voor zoveel mogelijk mensen, voor alle mensen die ge bereiken kunt" (Henau 1985:48). Overeenkomstig schrijft Jakob van Bruggen over de in Mat. 5:16 geschetste bediening dat deze 'voor het oog van alle volken' (van Bruggen 2004:91) moet plaatsvinden.

\section{De bewegingsrichting van de apostolische bediening}

In de vorige sectie is vastgesteld dat Jezus zijn discipelen in Mat. 5:13-16 een universalistische bediening opdraagt. Nu zal de bewegingsrichting van deze bediening worden bestudeerd. De vraag is of deze bediening centripetaal of centrifugaal (of allebei) is. Met andere woorden: verwacht Jezus dat de 'mensen' centripetaal naar de discipelen komen of dat de discipelen (ook) als zendelingen centrifugaal naar de 'mensen' gaan om hun licht te brengen?

Uitleggers die voor de eerste interpretatie pleiten doen dit op basis van Mat. 5:14 waar Jezus tot zijn discipelen zegt: 'Jullie zijn het licht in de wereld. Een stad die boven op een berg ligt, kan niet verborgen blijven.' De combinatie van de woorden 'licht' ( $\phi \hat{\omega} s)$, 'stad'

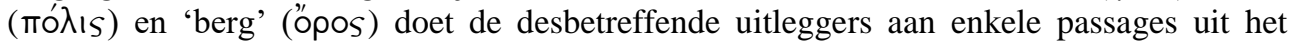
Oude Testament en andere joodse teksten denken die over een toekomstige pelgrimstocht van de volkeren naar de berg Sion (de zog. Völkerwallfahrt) spreken (vgl. bijvoorbeeld: Jes. 2:2-5; 60:1-3; Tob. 13:13). In Tob. 13:11 bijvoorbeeld wordt de stad Jeruzalem (vgl. Tob. 13:9) met de volgende woorden toegesproken: 'Een stralend licht zal van je uitgaan, het schijnt tot aan de grenzen der aarde. Van verre zullen vele volken naar je toe komen, van de uiteinden der aarde trekken ze op naar je heilige naam, beladen met geschenken voor de koning van de hemel.' Door de 'stad' in Mat. 5:14 als verwijzing naar Jeruzalem te verstaan, zien veel uitleggers in dit vers dus het oudtestamentische/joodse motief van de Völkerwallfahrt aanwezig, wat zij dan met betrekking tot de discipelen anders uitleggen, d.w.z. de discipelen worden als de bestemming van de komst van de heidenen gezien (vgl. bijv. von Rad 1948/1949:447; Šoltés 2004:186; Betz 1995:161). Keulers schrijft in zijn commentaar op Mat. 5:14: 'Hij [Jesus (sic)] [wil] de leerlingen ... voorstellen als een

\footnotetext{
8 Nederlandse tekst afkomstig uit de Herziene Statenvertaling.
} 
uiterlijke maatschappij, die voor alle mensen zichtbaar is, als een nieuwe Sionstad, waarheen alle mensen toestromen (Is. 2,1-5)' (Keulers 1950:70). J.T. Nielsen stelt: 'Wanneer Jes. 2:2-5 de achtergrond vormt ..., dan vormen de "gij" van dit vers het nieuwe Jeruzalem, de stad op de berg, het licht der wereld' (Nielsen 1971:102). Het probleem met deze interpretatie is dat in Mat. 5:14 noch mó $\lambda_{15}$ noch opos met een lidwoord worden gebruikt. Daarom is het niet waarschijnlijk dat in Mat. 5:14 aan Jeruzalem als de stad op de berg Sion gedacht is (vgl. Nolland 2005:214). Veeleer lijkt het zo te zijn dat Jezus in Mat. 5:14 gewoon het beeld van een stad op een berg gebruikt om daarmee het effect van licht te benadrukken. Omdat mó $\lambda_{\mathrm{s}}$ in Mat. 5:14 niet op Jeruzalem doelt kan dit vers niet als verwijzing naar de Völkerwallfahrt en dus ook niet als een centripetaal universalisme worden opgevat (vgl. Paschke 2011:647).

Er zijn echter verschillende overwegingen die ervoor pleiten Mat. 5:14 als uitdrukking van een centrifugaal universalisme te zien: de achtergrond van de Mattheaanse term 'het

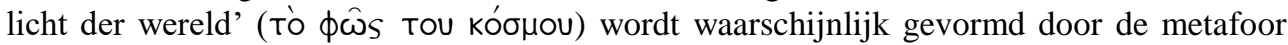

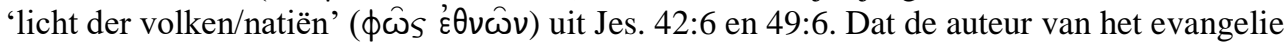
van Mattheüs de Jesajaanse metafoor $\phi \hat{\omega} s$ $\dot{\theta} \theta \omega \hat{\omega} v$ waarschijnlijk als uitdrukking van een centrifugaal universalisme ziet wordt duidelijk in Mat. 12:18-21, waar Jes. 42:1-4 geciteerd wordt. In Mat. 12:18 wordt het werkwoord $\alpha_{\alpha}^{\prime} \propto \gamma \gamma \gamma^{\prime} \lambda \lambda \omega$ gebruikt. Twee dingen zijn in dit verband cruciaal: ten eerste beschrijft ${ }^{\alpha} \pi \propto \gamma \gamma^{\prime} \hat{\varepsilon}^{\prime} \lambda \omega$ in de rest van het evangelie uitsluitend een centrifugale beweging van boodschappers (Mat. 2:8; 8:33; 11:4; 14:12; 28:8, 10, 11). Het lijkt er dus op dat de auteur van het evangelie van Mattheüs door het gebruik van $\alpha_{\alpha}^{\prime} \pi \gamma \gamma^{\prime} \hat{\varepsilon}^{\prime} \lambda \omega$ een centrifugaal universalisme aan de bediening van de Godsknecht toewijst. Ten tweede heeft de Mattheaanse bewoording $\alpha^{\prime} \pi \alpha \gamma \gamma^{\prime} \hat{\varepsilon} \lambda \omega$ geen equivalent in de Hebreeuwse Bijbel noch de Septuagint, waar in Jes. 42:1 respectievelijk de wat bewegings-

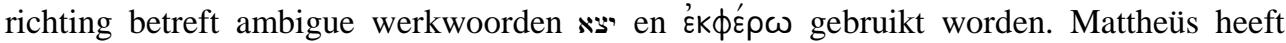
$\alpha_{\alpha} \pi \gamma \gamma^{\prime} \dot{\varepsilon} \lambda \omega$ en de daarmee gepaard gaande centrifugale beweging dus niet uit een bestaande versie van Jes. 42:1 overgenomen maar blijkt veeleer bewust daarvoor te hebben gekozen. Mattheüs associeert de in Jes. 42:1-4 geschetste bediening van de Godsknecht en daarmee waarschijnlijk ook de metafoor $\phi \hat{\omega} s$ 'ं $\theta v \hat{\omega} v$ van twee verzen verder (Jes. 42:6) - dus met een centrifugaal universalisme. Dat een dergelijke interpretatie van de Jesajaanse metafoor $\phi \hat{\omega} s$ है$\theta \nu \omega \hat{v} v$ in vroegchristelijke kringen niet ongewoon was maakt Hand. 13:47 duidelijk waarin Paulus en Barnabas hun centrifugale wending tot de heidenen (vgl. Hand. 13:46) rechtvaardigen met een citaat van Jes. 49:6. Omdat dus de metafoor $\phi \hat{s} s$ $\dot{\theta} v \hat{\omega} v$ door Mattheüs (en andere vroegchristelijke schrijvers) als uitdrukking van een centrifugaal universalisme wordt beschouwd, ligt het voor de hand dat ook de metafoor tó $\phi \hat{\omega}$ s toû

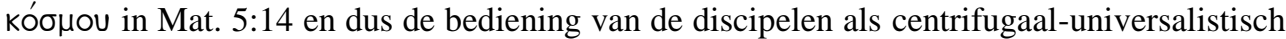
wordt voorgesteld. Michael F. Bird schrijft over Mat. 5:14: 'Manson, Evans, and Jeremias all see in this saying an echo of the Isaiah "light" passages and interpret the utterance in the context of God's light reaching the nations. If so, then Jesus was intimating that his disciples were to have a centrifugal and redemptive role, like the Servant in Isaiah, and were to be emissaries and heralds of the kingdom of God to the nations' (Bird 2006:126).

Omdat de universalistische bediening van de discipelen volgens Mat. 5:13-16 een centrifugale richting heeft kunnen deze als 'missionarissen' worden gezien. Het Latijnse woord missio betekent 'zending' en houdt dus per definitie een centrifugale beweging in. 


\section{Het tijdstip van de apostolische bediening}

Tot nu toe is aannemelijk gemaakt dat de Mattheaanse Jezus zijn discipelen in Mat. 5:13-16 een universalistische bediening opdraagt die een centrifugale bewegingsrichting heeft. $\mathrm{Nu}$ zal worden ingegaan op de vraag wanneer deze bediening plaats vindt in het Mattheaanse verhaal, d.w.z. wanneer het begint en eindigt.

\section{Het begin van de apostolische bediening}

Grammaticale overwegingen

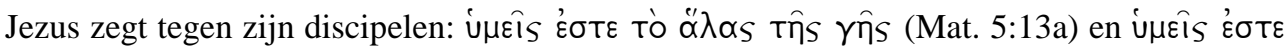

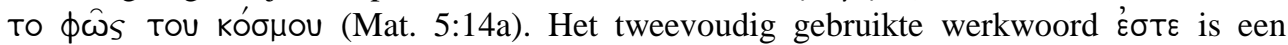
indicatief presens van Eiłú ('zijn'). De indicatief presens verwijst normaal gesproken naar de tegenwoordige tijd maar kan ook betrekking op de toekomst hebben (von Siebenthal 2011:320-321 [\$§ 197a en c]). In dit laatste geval staat de indicatief presens vaak in verband met een op de toekomst wijzende tijdsbestemming (Blass/Debrunner 2001:267 [ $\$$ 323 voetnoot 1]), welke in Mat 5:13a en 14a echter ontbreekt. Daarom is het waarschijnlijk dat de betreffende uitspraken van Jezus over zijn discipelen betrekking op de tegenwoordige tijd hebben, d.w.z. de discipelen horen van Jezus dat zij tegenwoordig zout en licht zijn.

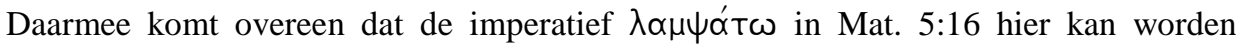
opgevat als een ingressieve aoristus (Deines 2004:188, voetnoot 254). P.M. Hensels schrijft in zijn grammatica: 'Bij sommige (duratieve) werkwoorden kan de aoristus het begin van de handeling aangeven; we spreken dan van een aoristus ingressivus' (Hensels 2008:239 [ $\$$ 13.8c]). De imperatief van de ingressieve aoristus is een bevel met de (langer aanhoudende) handeling te beginnen (Hoffmann/von Siebenthal 2007:362-363 [§ 212d]). In de grammatica van Friedrich Blass en Albert Debrunner wordt over de imperatief van de aoristus gezegd: 'Ingressiv drückt er das Zustandekommen des Verhaltens im Gegensatz zum bisherigen aus.' Als voorbeeld wordt dan naar de imperatief úmотর́ $\gamma \eta \tau \varepsilon ~ \tau \hat{\omega} \theta \varepsilon \hat{\omega}$ in Jak. 4:7 verwezen wat als 'onderwerp u (vanaf nu) aan God' opgevat wordt (Blass/Debrunner

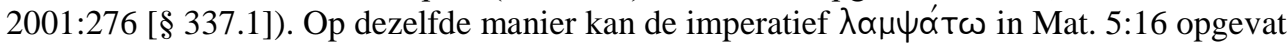
worden als een bevel met onmiddellijke kracht: De Mattheaanse Jezus verwacht van zijn discipelen dat zij direct na afloop van de Bergrede hun universalistische bediening aanvatten.

Op basis van deze grammaticale overwegingen kan Mat. 5:13-16 als volgt geparafraseerd worden: 'Jullie zijn $n u$ al het zout van de aarde ... Jullie zijn $n u$ al het licht van de wereld ... Zo moet jullie licht vanaf nu schijnen voor de mensen!'9

Overwegingen wat betreft de onderzoeksgeschiedenis

De tot nu toe in deze bijdrage ontwikkelde positie dat de universalistische bediening van de discipelen volgens Mat. 5:13-16 centrifugaal is en meteen na afloop van de Bergrede begint is een novum in de nieuwtestamentische wetenschap.

Sommige exegeten zijn het eens met het tweede punt, maar ontkennen het eerste door respectievelijk te stellen dat de universalistische bediening van de discipelen in het verhaal weliswaar de tegenwoordigheid betreft maar wel een centripetale richting heeft (Wiefel

Vgl. Hagner 1993:100: 'Since the disciples are the light of the world (v 15), they are now exhorted to let their light shine.' 
1998:96; Nissen 1999:28). Eerder werd al beargumenteerd dat het niet aannemelijk is dat de in Mat. 5:13-16 geschetste universalistische bediening van de discipelen als centripetaal wordt beschouwd.

Andere onderzoekers zijn het daarentegen eens met het eerste punt, maar ontkennen het tweede door respectievelijk te stellen dat Jezus zijn discipelen in Mat. 5:13-16 weliswaar een universalistische bediening met een centrifugale richting opdraagt, maar dat deze opdracht van de discipelen niet meteen na de Bergrede maar pas na Jezus' opstanding verwezenlijkt wordt. Deze uitleggers vatten Mat. 5:13-16 dan op als een anticipatie op de zendingsopdracht van Mat. 28:18-20. John C. Fenton schrijft bijvoorbeeld met betrekking tot het 'licht' in Mat. 5:16: 'This light will be displayed to all when Jesus sends the disciples to all nations (28) ${ }^{19}$, (Fenton 1963:84; vgl. Konradt 2007:302). Het blijkt dan dat de aan het begin van dit artikel geschetste tweedeling van het Mattheaanse verhaal uitleggers dwingt om Mat. 5:13-16 als niet meer dan een anticipatie op Mat. 28:19 te beschouwen (vgl. Walker 1967:99). De exegetische positie van Mat. 5:13-16 als anticipatie op het zendingsbevel van Mat. 28:19 zal nu narratief-kritisch getoetst worden.

\section{Narratief-kritische overwegingen}

Narratief-critici zijn het erover eens dat het Mattheaanse verhaal van begin tot eind moet worden gelezen. Zo schrijft Joop Smit bijvoorbeeld over de literaire benadering van het evangelie van Mattheüs dat 'de aandacht zich vooral op de manier [richt] waarop het verhaal zich van het begin tot het eind ontwikkelt' (Smit 2007:8; vgl. Weren 1994:8). Maar narratief-critici zijn het er niet over eens of het Mattheaanse verhaal voor een eerste lezing (first-time reading) (vgl. Edwards 1985:9) of een herhaaldelijke lezing (rereading) ${ }^{10}$ is geschreven. Beide lezingen worden hier besproken waarbij zal worden aangetoond dat Mat. 5:13-16 noch bij een eerste noch bij een herhaaldelijke lezing slechts geïnterpreteerd kan worden als anticipatie op Mat. 28:18-20.

\section{Eerste lezing}

Een lezer die het verhaal van Mattheüs voor de eerste keer doorleest is zich bij het lezen van Mat. 5:13-16 (nog) niet bewust van de na Pasen, d.w.z. pas aan het eind van het verhaal door Jezus aan zijn discipelen gegeven, zendingsopdracht (Mat. 28:18-20) en kan de eerste tekst daarom überhaupt niet zien als anticipatie op een eventuele tweede tekst. Veeleer zal Mat. 5:13-16 door de lezer als een op zichzelf staande universalistische zendingsopdracht van Jezus aan zijn discipelen worden opgevat die meteen na de Bergrede te verwezenlijken is. In dit verband valt echter nog meer te zeggen. Exegeten die Mat. 5:13-16 als anticipatie op Mat. 28:19 zien, lezen de eerste tekst niet alleen maar in het licht van de universalistische zendingsopdracht van Mat. 28:19 maar ook in het licht van de particularistische zendingsopdrachten van Mat. 10:5-6 en 15:24. Dit wordt bijvoorbeeld zichtbaar in het commentaar van Francis Wright Beare op Mat. 5:13-16:

Matthew is well aware that Jesus himself restricted his own mission to Israel, and responded to appeals from Gentiles only under a kind of compulsion (8:5-13; 15:21-28), but he perceives that the effects of his work are not destined to be limited to Israel. By placing these words at the beginning of Jesus' ministry, Matthew foreshadows the charge

10 Vgl. Weren 1994:8: 'Pas na herhaalde lezing krijg ik enig zicht op het geheel en kan ik allerlei relaties leggen die mij in de eerste instantie nog ontgingen.' 
that will be given by the risen Christ: 'Go into all the world and make disciples of all nations' (28:19) (Beare 1981:137).

Een lezer die het Mattheaanse verhaal echter voor het eerst doorneemt, kent Mat. 10:5-6 en 15:24 nog niet wanneer hij of zij de Bergrede leest. Het particularisme, dat pas in Mat. 10:5-6 geïntroduceerd (en later in Mat. 15:24 herhaald) wordt is in de Bergrede voor de lezer nog onbekend. Daarom is er geen aanleiding om de onmiddellijke verwezenlijking van het centrifugaal universalisme van Mat. 5:13-16 als onvertrouwd in het Mattheaanse verhaal en dus als anticipatie op Mat. 28:19 te beschouwen.

\section{Herhaaldelijke lezing}

Een lezer die het verhaal van Mattheüs herhaaldelijk doorneemt is bij het lezen van Mat. 5:13-16 reeds vertrouwd met de zendingsopdracht uit Mat. 28:19 en zal de eerste tekst daarom in het licht van de tweede verstaan. Het is echter onwaarschijnlijk dat de lezer Mat. 5:13-16 als anticipatie op Mat. 28:19 ziet, omdat hij of zij niet alleen maar de niet van de hand te wijzen overeenkomsten (bijv. universalisme en centrifugale bewegingsrichting) maar tenminste ook één behoorlijk verschil tussen deze twee teksten ziet: Volgens Mat. 5:13-16 zijn in eerste instantie de - eventueel van een mondelinge boodschap voorziene ${ }^{11}$ 'goede daden' ( $k \alpha \lambda \propto \alpha$ ' $\varepsilon \rho \gamma \alpha)$ van de discipelen het middel van hun zending. Wolfgang Wiefel spreekt daarom terecht van een 'Mission der guten Taten' (Wiefel 1998:97). In Mat. 28:18-20 ziet de zaak er echter heel anders eruit. In deze verzen geven de twee modale

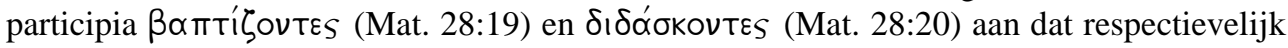
doop en leer de middelen van zending zijn. In dit verband blijven goede daden onvermeld. Omwille van dit behoorlijke verschil tussen Mat. 5:13-16 en Mat. 28:18-20 wat betreft de middelen van zending zou de lezer de eerste tekst onmogelijk als anticipatie op de tweede kunnen zien. Net zoals met een eerste lezing duidt ook een herhaaldelijke lezing er veeleer op dat Mat. 5:13-16 moet worden verstaan als een zelfstanding bevel.

Samenvattend kan dus gezegd worden dat het vanuit narratief-kritisch perspectief niet mogelijk is om Mat. 5:13-16 enkel als anticipatie op Mat. 28:18-20 te lezen. Op basis van zowel grammaticale als narratief-kritische overwegingen kan het universalistische zendingsbevel in Mat. 5:13-16 niet anders worden geïnterpreteerd dan dat het onmiddellijk na afloop van de Bergrede door de discipelen te verwezenlijken is.

\section{Het einde van de apostolische bediening}

Het einde van de in Mat. 5:13-16 opgedragen apostolische bediening kan op basis van Mat. 10:5b-6 duidelijk worden aangegeven: In deze verzen zegt de Mattheaanse Jezus in de context van de uitzending van zijn discipelen: 'Sla niet de weg naar de heidenen in en bezoek geen Samaritaanse stad. Ga liever op zoek naar de verloren schapen van het volk van Israël.' Hier wordt dus de tot nu toe universele zending van de discipelen tot 'de

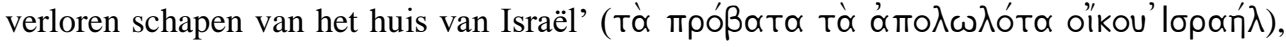

\footnotetext{
11 Hoe zouden de 'mensen' anders de goede daden van de discipelen met hun Vader in de hemel in verbinding brengen? (Mat. 5:16) Daar is toch een soort mondelinge verklaring voor nodig.
} 
d.w.z. tot het volk Israël, ${ }^{12}$ beperkt en op deze manier in een particularistische bediening gewijzigd. $^{13}$

De eerder gestelde vraag naar het tijdstip van de in Mat. 5:13-16 geschetste apostolische bediening kan nu afsluitend als volgt worden beantwoord: de Mattheaanse Jezus verwacht dat zijn discipelen onmiddellijk na afloop van de Bergrede (Mat. 5-7) met hun bediening beginnen. De verwezenlijking van deze bediening wordt echter in Mat. 10:5b-6 door Jezus onderbroken, omdat hij zijn discipelen dan opdraagt zich tijdens hun bediening enkel tot het volk Israël te richten.

\section{Samenvatting en conclusies}

In dit artikel is de in Mat. 5:13-16 geschetste apostolische bediening met betrekking tot het spanningsveld particularisme en universalisme narratief-kritisch bestudeerd, met de volgende resultaten: de reikwijdte van de bediening is universeel. De bediening richt zich dus tot joden en heidenen. De bewegingsrichting van de bediening is centrifugaal en kan daarom 'zending' (missio) worden genoemd. De discipelen dienen als zendelingen alle mensen ${ }^{14}$ tegemoet te treden. Wat het tijdstip van deze bediening betreft kan het volgende gezegd worden: het in Mat. 5:13-16 opgedragen universele zendingswerk begint meteen na afloop van de Bergrede (Mat. 5-7) en eindigt met Mat. 10:5-6, waar Jezus de bediening van zijn discipelen tot het volk Israël beperkt voordat hij hen in Mat. 28:19 weer tot alle volken uitzendt.

Wanneer de Mattheaanse Jezus zijn discipelen in Mat. 5:13-16 en dus al aan het begin van het verhaal een universele zending opdraagt staat deze tekst in spanning met de in de nieuwtestamentische wetenschap gevestigde tweedeling van het Mattheüs evangelie in een particularistische of centripetale universalistische fase voor en een centripetale universalistische fase $n a$ Pasen. Uitgaand van Mat. 5:13-16 zou men het verhaal van Mattheüs beter in drie fasen kunnen indelen: Een universalistisch begin (Mat. 4:18-10:4), een particularistische tussentijd (Mat. 10:5-28:17) en een universalistisch open einde (Mat. 28: 18-20). Dit resultaat wordt door de andere teksten van de Bergrede die betrekking hebben op de spanning tussen particularisme en universalisme (d.w.z. Mat. 5:47; 6:7-8, 31-32; 7:6, 24-27) niet ontkracht maar bevestigd.

\section{LITERATUURLIJST}

Beare, FW 1981. The Gospel According to Matthew: A Commentary, Oxford: Basil Blackwell.

Betz, HD 1995. The Sermon on the Mount: A Commentary on the Sermon on the Mount, Including the Sermon on the Plain (Matthew 5:3-7:27 and Luke 6:20-49

Minneapolis: Fortress. Hermeneia.

12 De frase ö́kou' lopań入 moet hier dus niet als genitivus partitivus, maar als genitivus epexegeticus opgevat worden.

13 De redenen voor deze beperking zijn zowel theologisch (Mat. 9:36) als pragmatisch (Mat. 9:37) van aard. Vgl. daarvor Paschke 2012:227-229.

14 Hier wordt dus helemaal geen verschil tussen mensen gemaakt. Alle mensen, onafhankelijk van hun afkomst, hebben dezelfde waarde - een waarheid die voordurend herhaald moet worden om elke vorm van apartheid te voorkomen en te bestrijden. 
Beutler, J 1994. Ihr seid das Salz des Landes (Mt 5,13). In: C. Mayer, K. Müller,

G. Schmalenberg (red.), Nach den Anfängen fragen (Gießen: Selbstverlag des Fachbereichs 07; Gießener Schriften zur Theologie und Religionspädagogik des Fachbereichs Evangelische Theologie und Katholische Theologie und deren Didaktik der Justus-Liebig-Universität 8), blz. 85-94.

Bird, MF 2006. 'A Light to the Nations' (Isaiah 42:6 and 49:6): Inter-Textuality and Mission Theology in the Early Church. The Reformed Theological Review 65:122-131.

Blass, F \& Debrunner, A 2001. Grammatik des neutestamentlichen Griechisch, bearbeitet von F. Rehkopf. Göttingen: Vandenhoeck \& Ruprecht.

Carson, DA 1984. Matthew. In: FE Gæbelein (red.), The Expositor's Bible Commentary.

Deel 8. Matthew, Mark, Luke (Grand Rapids: Zondervan), blz. 1-599.

Deines, R 2004. Die Gerechtigkeit der Tora im Reich des Messias: Mt 5,13-20 als

Schlüsseltext der matthäischen Theologie. Tübingen: Mohr Siebeck.

Wissenschaftliche Untersuchungen zum Neuen Testament 177.

Dumbrell, WJ 1981. The Logic of the Role of the Law in Matthew V 1-20.

Novum Testamentum 23:1-21.

Edwards, R 1985. Matthew's Story of Jesus. Philadelphia: Fortress.

Fenton, JC 1963. The Gospel of St Matthew. Harmondsworth: Penguin. The Pelican Gospel Commentaries.

Gnilka, J 1993. Das Matthäusevangelium. Deel 1. Kommentar zu Kap. 1,1-13,58.

Freiburg: Herder. Herders Theologischer Kommentar zum Neuen Testament.

Grosheide, FW 1954. Het heilig evangelie volgens Mattheus. Kampen: Kok.

Commentaar op het Nieuwe Testament.

Hagner, DA 1993. Matthew 1-13. Dallas: Word. Word Biblical Commentary.

Henau, E 1985. Mt. 5,13-16: De leerlingen als zout en licht. In: Werkgroep Sacerdos (red.),

Dichtbij is Uw woord: Exegetisch commentaar bij de evangelieperikopen van

jaarcyclus A. Matteüs-evangelie (Mechelen/Leuven: Werkgroep Sacerdos), blz. 47-49.

Hensels, PM 2008. Nieuwtestamentisch Grieks: Een beknopte grammatica.

Bussum: Coutinho.

Hoffmann, EG \& Von Siebenthal, H 2007. Griechische Grammatik zum Neuen Testament,

Riehen: Immanuel.

Keulers, J 1950. Het evangelie volgens Mattheüs. Roermond: Romen \& Zonen.

De boeken van het Nieuwe Testament 1 .

Kingsbury, JD 1988. Matthew as Story. Philadelphia: Fortress.

Konradt, M 2007. Israel, Kirche und die Völker im Matthäusevangelium. Tübingen:

Mohr Siebeck. Wissenschaftliche Untersuchungen zum Neuen Testament 215.

Levine, A-J 1988. The Social and Ethnic Dimensions of Matthean Salvation History:

'Go nowhere among the Gentiles' (Matt. 10:5b). Lewiston: Edwin Mellen.

Studies in the Bible and Early Christianity 14.

Luz, U 2007. Matthew 1-7: A Commentary. Minneaplis: Fortress. Hermeneia.

Luz, U 2008. Die Jesusgeschichte des Matthäus. Neukirchen-Vluyn: Neukirchener.

Manson, TW 1979. The Sayings of Jesus: As Recorded in the Gospels According to

St. Matthew and St. Luke Arranged with Introduction and Commentary.

Grand Rapids: Eerdmans. 
Metzger, BM 2001. A Textual Commentary on the Greek New Testament. Stuttgart:

Deutsche Bibelgesellschaft.

Nielsen, JT 1971. Het evangelie naar Mattheüs. Deel 1. Nijkerk: Callenbach.

De prediking van het Nieuwe Testament.

Nissen, J 1999. New Testament and Mission: Historical and Hermeneutical Perspectives. Frankfurt a.M.: Peter Lang.

Nolland, J 2005. The Gospel of Matthew: A Commentary on the Greek Text. Grand Rapids: Eerdmans. The New International Greek Testament Commentary.

Paschke, B 2011. Ein Kommen und Gehen: Wie konsequent wird im Matthäusevangelium zwischen zentripetalem und zentrifugalem Universalismus unterschieden?'

In D. Senior (red.), The Gospel of Matthew at the Crossroads of Early Christianity (Leuven: Peeters, Bibliotheca Ephemeridum Theologicarum Lovaniensum 243), blz. 637-652.

Paschke, B 2012. Particularism and Universalism in the Sermon on the Mount:

A Narrative-Critical Analysis of Matthew 5-7 in the Light of Matthew's View on

Mission. Münster: Aschendorff. Neutestamentliche Abhandlungen, Neue Folge 56.

Pattarumadathil, H 2008. Your Father in Heaven: Discipleship in Matthew as a Process of Becoming Children of God. Rome: Editrice Pontificio Instituto Biblico. Analecta Biblica: Investigationes Scientificae in Res Biblicas 172.

Ridderbos, H 1952. Het evangelie naar Mattheüs: Opnieuw uit den grondtekst vertaald en verklaard. Deel 1, Hoofdstuk 1:1-16:12. Kampen: Kok. Korte verklaring der Heilige Schrift.

Sand, A 1986. Das Evangelium nach Matthäus. Regensburg: Pustet. Regensburger Neues Testament.

Smit, J 2007. Het verhaal van Matteüs: Sleutelpassages uit zijn evangelie. Zoetermeer/Averbode: Boekencentrum.

Šoltés, P 2004. 'Ihr seid das Salz des Landes, das Licht der Welt: Eine exegetische Untersuchung zu Mt 5,13-16 im Kontext. Frankfurt a.M.: Peter Lang. Europäische Hochschulschriften, Reihe XXIII [Theologie] 782.

Tisera, G 1993. Universalism According to the Gospel of Matthew. Frankfurt a.M.: Peter Lang. European University Studies, Series XXIII [Theology] 482.

Van Bruggen, J 2004. Matteüs: Het evangelie voor Israël. Kampen: Kok. Commentaar op het Nieuwe Testament, Derde serie.

Von Rad, G 1948/1949. Die Stadt auf dem Berge. Evangelische Theologie 8: 439-447.

Von Siebenthal, H 2011. Griechische Grammatik zum Neuen Testament, Neubearbeitung und Erweiterung der Grammatik Hoffmann / von Siebenthal. Gießen: Brunnen.

Walker, R 1967. Die Heilsgeschichte im ersten Evangelium. Göttingen: Vandenhoeck \& Ruprecht. Forschungen zur Religion und Literatur des Alten und Neuen Testaments 91.

Weren, W 1994. Belichting van het bijbelboek Matteüs. 's-Hertogenbosch/Brugge: Katholieke Bijbelstichting.

Wiefel, W 1998. Das Evangelium nach Matthäus. Leipzig: Evangelische Verlagsanstalt. Theologischer Handkommentar zum Neuen Testament 1. 